\title{
Dextran Sodium Sulphate Colitis Mouse Model: Traps and Tricks
}

\author{
Martina Perše and Anton Cerar \\ Institute of Pathology, Medical Experimental Centre, Medical Faculty, University of Ljubljana, Zaloška 4, 1105 Ljubljana, Slovenia \\ Correspondence should be addressed to Martina Perše, martina.perse@mf.uni-lj.si
}

Received 9 December 2011; Accepted 5 March 2012

Academic Editor: Oreste Gualillo

Copyright ( 12012 M. Perše and A. Cerar. This is an open access article distributed under the Creative Commons Attribution License, which permits unrestricted use, distribution, and reproduction in any medium, provided the original work is properly cited.

\begin{abstract}
Inflammatory bowel disease (IBD) is a complex multifactorial disease of unknown etiology. Thus, dozens of different animal models of IBD have been developed in past decades. Animal models of IBD are valuable and indispensable tools that provide a wide range of options for investigating involvement of various factors into the pathogenesis of IBD and to evaluate different therapeutic options. However, the dextran sulphate sodium (DSS-) induced colitis model has some advantages when compared to other animal models of colitis. It is well appreciated and widely used model of inflammatory bowel disease because of its simplicity. It has many similarities to human IBD, which are mentioned in the paper. In spite of its simplicity and wide applicability, there are also traps that need to be taken into account when using DSS model. As demonstrated in the present paper, various factors may affect susceptibility to DSS-induced lesions and modify results.
\end{abstract}

\section{Introduction}

Inflammatory bowel disease (IBD) is a complex multifactorial disease [1-3]. It commonly refers to ulcerative colitis (UC) and Crohn's disease (CD), the two chronic conditions that involve inflammation of the intestine. IBD is common in developed countries, with up to 1 in 200 of individuals of Northern European region affected by these disease [4]. Patients with IBD present several clinically challenging problems for physicians. Despite recent advances in treatment, there remains a need for a safe, well-tolerated therapy with a rapid onset, and increased capacity for maintaining long-term remission [5].

In past decades, dozens of different animal models of IBD have been developed. These models can be broadly divided into spontaneous colitis models, inducible colitis models, genetically modified models, and adoptive transfer models [6-8]. Although these models do not represent the complexity of human disease, they are valuable and indispensable tools that provide a wide range of options for investigating involvement of various factors into the pathogenesis of IBD and evaluate different therapeutic options. Chemically induced murine models of intestinal inflammation are one of the most commonly used models because they are simple to induce, the onset, duration, and severity of inflammation are immediate and controllable. Both dextran sulphate sodium (DSS) and trinitrobenzene sulfonic acid (TNBS-) induced colitis are well-established animal models of mucosal inflammation that have been used for over 2 decades in the study of IBD pathogenesis and preclinical studies [6-8]. The DSS-induced colitis model has some advantages when compared to other animal models of colitis. For example, an acute, chronic, or relapsing model can be produced easily by changing the concentration of administration of DSS (and cycle in rats and other strains of mice). Moreover, dysplasia that resembles the clinical course of human UC occurs frequently in the chronic phase of DSS-induced colitis. DSS-induced model for studying colitis-associated carcinogenesis has been recently reviewed by others $[9,10]$. Furthermore, studies that validated DSS model by using different therapeutic agents for human IBD show that DSS-induced colitis can be used as a relevant model for the translation of mice data to human disease [11]. Thus, the aim of the present paper is to give a concise introduction of different factors that may be involved in the patogenesis of DSS-induced colitis and need to be taken into account when using this model. At the same time few aspects of applicability and further investigation of this model are mentioned. 


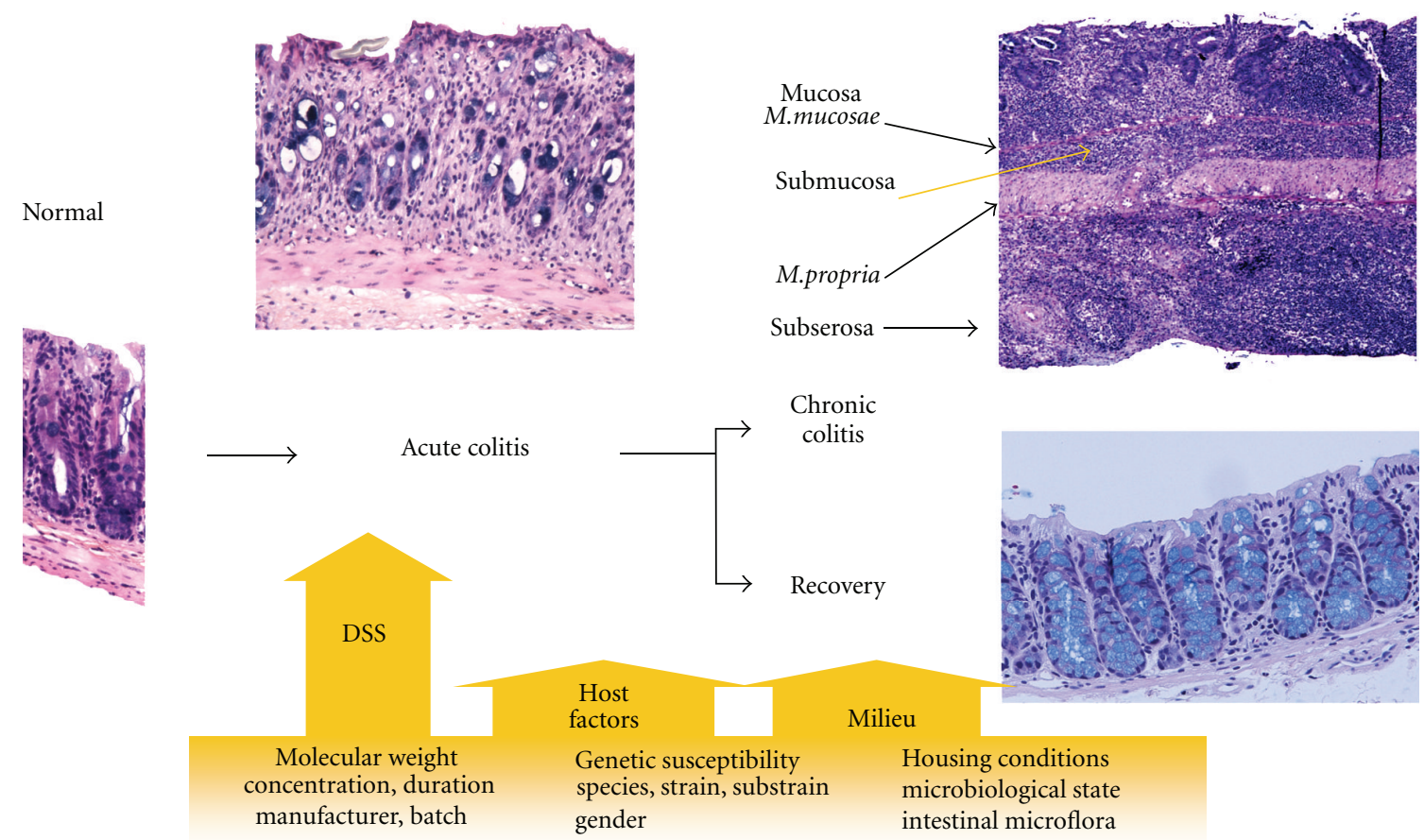

FIGURE 1: Schematic simplified representation of various factors that can influence the susceptibility, onset, severity, and responsiveness to DSS-induced colitis.

\section{Induction of DSS Colitis}

First report on the use of DSS dates back in the year 1985, when Ohkusa et al. published their investigation on DSSinduced colitis in hamsters [12]. Thereafter, DSS colitis was induced also in mice [13]. Today there are numerous studies using DSS-induced colitis model to investigate pathogenesis of colitis and different factors affecting colitis. Colitis is induced by addition of DSS to drinking water. Depending on the concentration, the duration, and frequency of DSS administration, the animals may develop acute or chronic colitis or even colitis-induced dysplastic lesions. Mice show differential susceptibilities and responsiveness to DSS-induced colitis. The varying responses to DSS appear to be dependent on not only DSS (concentration, molecular weight, duration of DSS exposure, manufacturer, and batch) but also genetic (strain and substrain, gender) and microbiological (microbiological state and intestinal flora) factors of animal, which are disscussed in the present paper (Figure 1). Colitis onset and severity may vary with many of these factors. Stress can be one of them [14]. Differences in the DSS susceptibility do not correlate with differences in the consumption of DSS-supplemented water [15]. However, there is a need to monitor DSS consumption, especially when animals are exposed to different therapeutic strategies that may lower consumption of DSS (increased fluid intake or thirst) [16].

\section{The Molecular Weight of DSS}

DSS is sulfated polysaccharide with a highly variable molecular weight, ranging from $5 \mathrm{kDa}$ to up to $1400 \mathrm{kDa}$. It was found that the molecular weight of DSS is very important factor in the induction of colitis [17] or colitis-induced dysplastic lesions (carcinogenicity) [18]. The severity of colitis [17] and carcinogenic activity [18] differs with the administration of DSS at different molecular weights (i.e., $5 \mathrm{kDa}, 40 \mathrm{kDa}$, and $500 \mathrm{kDa}$ ). The most severe colitis in $\mathrm{BALB} / \mathrm{c}$ mice was observed when mice were treated with DSS of $40 \mathrm{kDa}$ molecular weight, while mice treated with DSS of $5 \mathrm{kDa}$ developed milder form of colitis. Mice treated with DSS of $500 \mathrm{kDa}$ had no lesions in the large bowel [17]. Similarly, carcinogenic activity in colon was induced by DSS of $54 \mathrm{kDa}$, while DSS of larger $(520 \mathrm{kDa})$ or smaller $(9.5 \mathrm{kDa})$ molecular weights induced no carcinogenic activity [18]. Examination of uptake and tissue distribution of DSS by histochemical techniques showed that failure in the induction of colitis with $500 \mathrm{kDa}$ DSS is due to its high molecular weight that prevents passage of the molecule through the mucosal membrane [17]. Molecular weight of DSS can affect location of colitis as well. Mice treated with $40 \mathrm{kDa}$ DSS developed most severe diffuse colitis in the middle and distal third of the large bowel, while mice treated with $5 \mathrm{kDa}$ DSS developed relatively patchy lesions mainly in the cecum and upper colon [17].

3.1. Uptake and Tissue Distribution of DSS. The histochemical analyses of uptake and tissue distribution of DSS at $40 \mathrm{kDa}$ molecular weight demonstrated that DSS penetrates the mucosal membrane in the intestine. One day after DSS treatment small amounts of DSS were found in macrophages in large bowel and mesenteric lymph nodes and in the liver Kupffer cells. At day 3 DSS was noticed in a few macrophages 


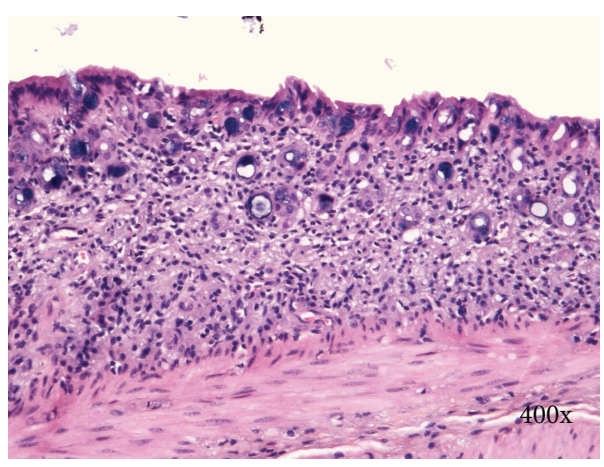

(a)

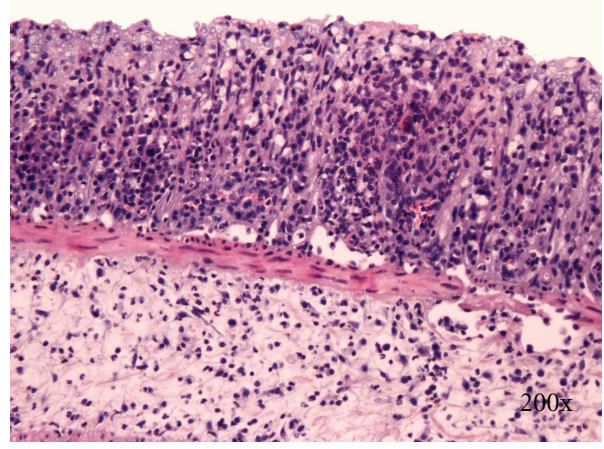

(b)

Figure 2: (a) Disappearance of crypts. (b) Erosion and phlegmonous inflammation of mucosa and submucosa. Kreyberg trichrom stain (acid mucopolysaccharides are stained blue). C57BL/6JOlaHsd female mice are exposed to 3\% DSS solution for 5 days followed by drinking water for 7 days.

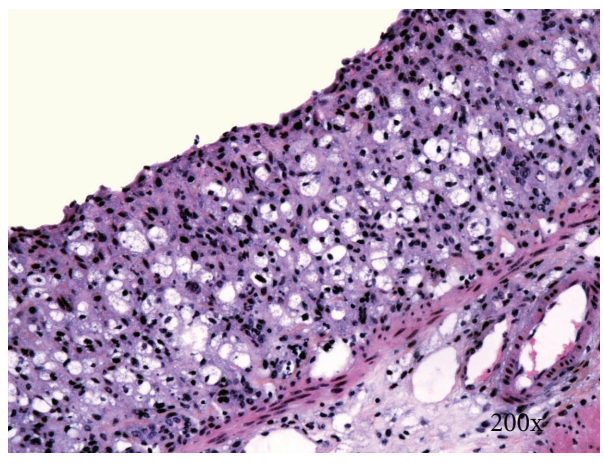

(a)

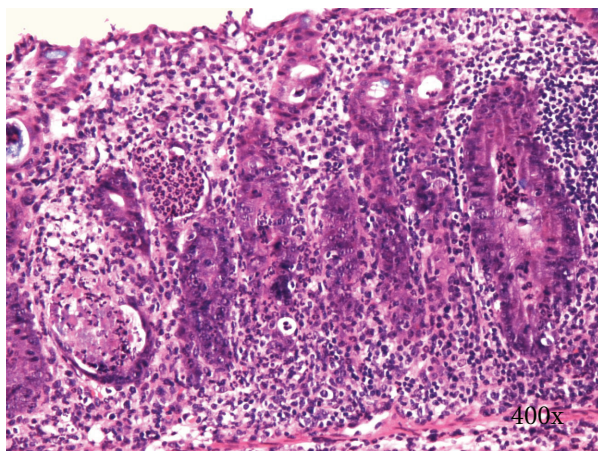

(b)

Figure 3: (a) Vacuolar hydropic degeneration of cells. (b) Epithelial necrosis, cryptitis, and crypt abscesses. Kreyberg trichrom stain (acid mucopolysaccharides are stained blue). C57BL/6JOlaHsd female mice exposed to 3\% DSS solution for 5 days followed by drinking water for 21 days.

in the spleen and 7 days after the start of 5 day DSS treatment in the kidney and in a few macrophages in the small intestine. DSS was seen in the liver Kupffer cells even 8 weeks after DSS removal [19]. During chronic phase of DSS colitis, considerable amounts of DSS were also found in the spleen [20]. In other organs and tissues (for instance brain, lung, heart, thymus, stomach, and duodenum), DSS was not observed [19]. Major excretion routes of DSS are urine and feces. Thus, presence of DSS in the epithelial cells of the proximal renal tubules after 7 days of DSS treatment is an indication of the excretion process of absorbed DSS [19]. DSS is resistant to degradation by intestinal microflora or the effects of different $\mathrm{pH}$ conditions (4.0-7.5) and anaerobic incubation [21].

\section{Clinical and Histological Features of DSS-Induced Colitis}

Clinical and histopathological features of DSS-colitis reflect those seen in human IBD. Acute colitis is usually induced by continuous administration of 2-5\% DSS for short period (49 days). Chronic colitis may be induced by continuous treatment of low concentrations of DSS or cyclical administration of DSS. For instance, 4 cycles of DSS treatment for 7 days followed by 10 days of water (Table 4). Clinical manifestation of DSS colitis in acute phase may include weight loss, diarrhea, occult blood in stools, piloerection, anaemia, and eventually death. However, clinical manifestations in chronic phase of colitis usually do not reflect severity of inflammation or histologic features found in large bowel.

Histological changes in DSS-induced colitis can be classified as acute (early) and chronic (advanced). Typical histological changes of acute DSS-colitis are mucin depletion, epithelial degeneration, and necrosis leading to disappearance of epithelial cells (Figure 2(a)). The latter is accompanied by neutrophils infiltration of lamina propria and submucosa, cryptitis, crypt abscesses (Figures 3(b) and 4), and phlegmonous inflammation in mucosa and submucosa (Figure 2(b)). Usually also shallow erosions appear (Figure 2(b)). Rarely there is a vacuolar hydropic degeneration of cells (Figure 3(a)). Transepithelial migration of neutrophils into mucosal epithelium is termed cryptitis. Migration of numerous neutrophils through mucosal epithelium into crypt lumen results in the formation of crypt abscess. Cryptitis and crypt abscesses are common histological feature of human IBD but rarely reported in DSS-induced colitis 


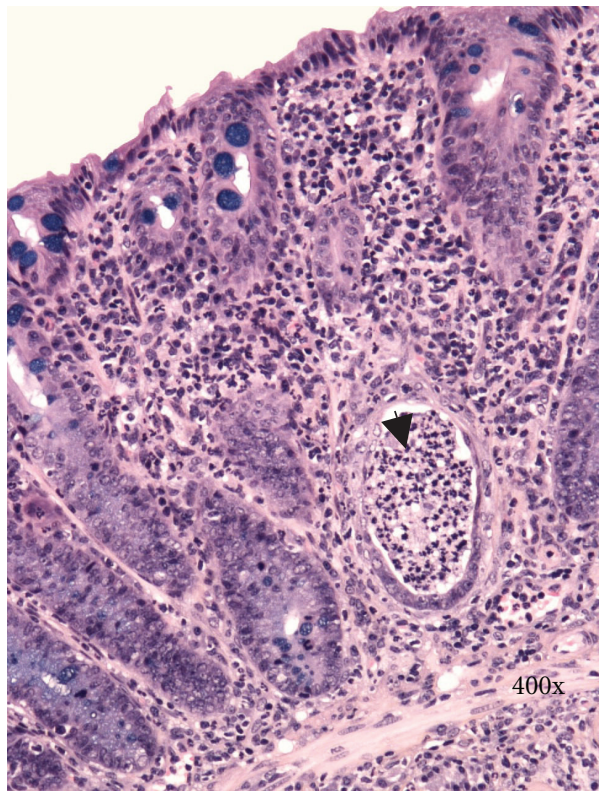

(a)

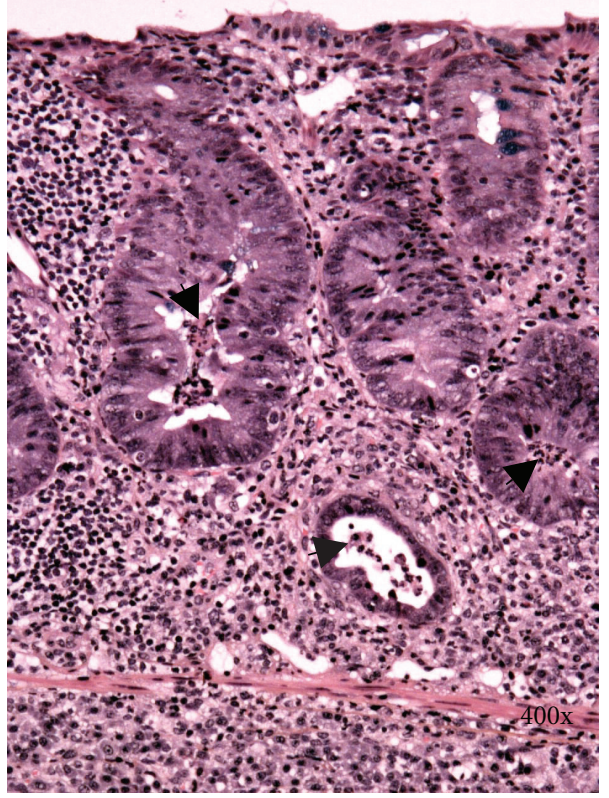

(b)

FIGURE 4: Arrows denote crypt abscesses (neutrophils) in the lumen of crypts. Kreyberg trichrom stain (acid mucopolysaccharides are stained blue). C57BL/6JOlaHsd male mice are exposed to 3\% DSS solution for 5 days followed by drinking water for (a) 7 days and (b) 28 days.

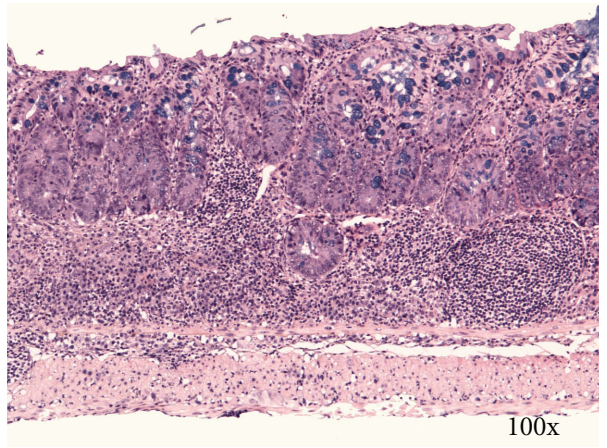

(a)

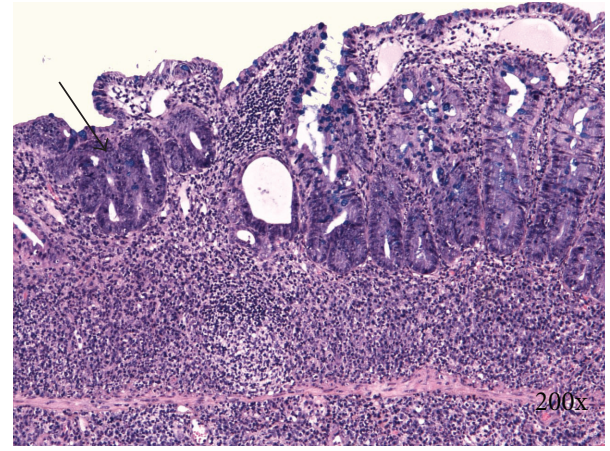

(b)

Figure 5: (a) Mononuclear leucocytes infiltration, crypt architectural disarray, and deep mucosal lymphocytosis. (b) Focally there is a moderate epithelial regeneratory atypia simulating dysplasia (arrow). Kreyberg trichrom stain (acid mucopolysaccharides are stained blue). C57BL/6JOlaHsd male mice are exposed to 3\% DSS solution for 5 days followed by drinking water for 28 days.

using haematoxylin-eosin staining method [22]. In contrast, we found cryptitis and crypt abscesses in half of DSStreated C57BL/6JOlaHsd mice, while in BALB/cAnNHsd mice cryptitis was rarely observed (unpublished data). However, we used Kreyberg-Jareg trichrom staining method that differentially stains acid mucopolysaccharides blue and thus contributes to better distinction between normal and aberrant mucosa. Interestingly, the presence of neutrophils in the epithelial lining of colon mucosa (cryptitis) and in the lumen of crypts (crypt abscess) was reported in DSS-treated C57BL/6OlaHsd mice when investigators used immunofluorescent staining against neutrophils [23].

Chronic changes appear few weeks after DSS application. They consist of mononuclear leucocytes infiltration, crypt architectural disarray (Figure 5(a)), increas- ing the distance (widening of the gap) between crypt bases and muscularis mucosa, deep mucosal lymphocytosis (Figure 4(a)), and transmural inflammation (Figure 6). It is widely believed that transmural inflammation is infrequent feature of DSS-induced colitis. In contrast, we observed transmural inflammation in C57BL/6JOlaHsd mice as well as in BALB/cAnNHsd mice, consonant with observation by Melgar et al. [22]. Moreover, in chronic colitis of C57BL/6JOlaHsd mice we even observed transmural inflammation with lymphoid follicles (Figure 6(b)), which is histological feature of Crohn's disease and was until now not observed in DSS colitis model.

Rarely reported characteristic change is also reepithelisation of rectal and distal colonic erosions by squamous epithelium that evidently originates from anal squamous 


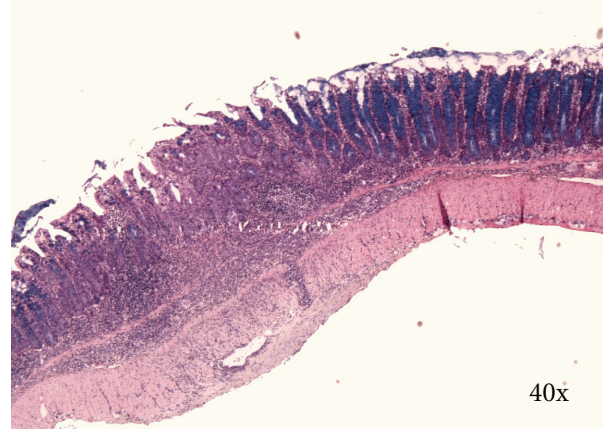

(a)

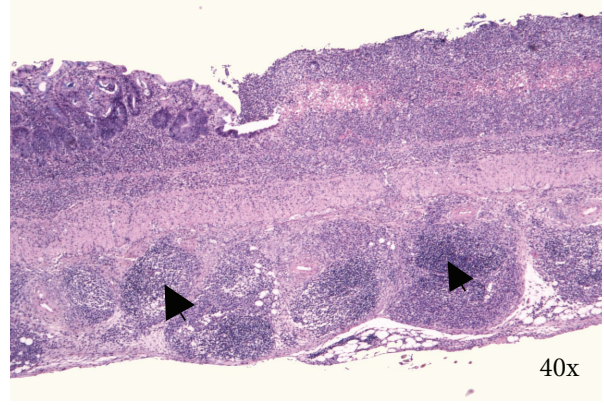

(b)

Figure 6: (a) Focal transmural chronic colitis (skip lesion). C57BL/6JOlaHsd female mice are exposed to 3\% DSS solution for 5 days followed by drinking water for 28 days. (b) Transmural inflammation with lymphoid follicles in subserosa (arrows) and chronic erosion. C57BL/6JOlaHsd female mice are exposed to 3\% DSS solution for 9 days followed by drinking water for 28 days. Kreyberg trichrom stain (acid mucopolysaccharides are stained blue).

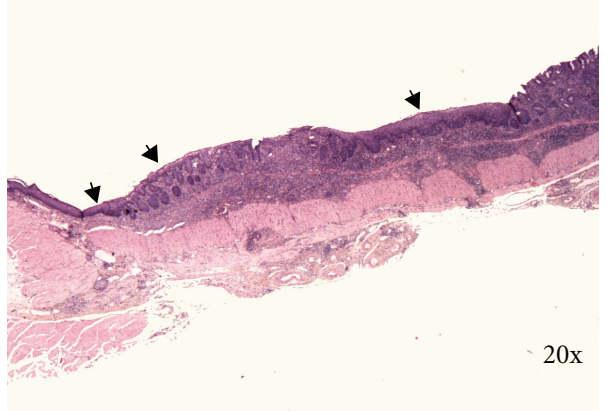

(a)

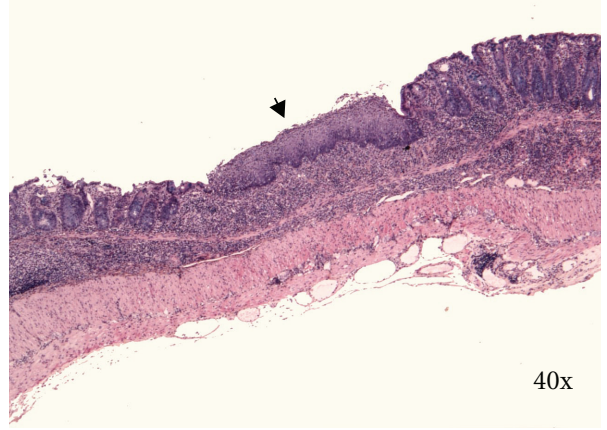

(b)

Figure 7: (a) and (b) reepithelisation of rectal and distal colonic erosion by squamous epithelium (arrows). C57BL/6JOlaHsd male mice are exposed to 3\% DSS solution for 5 days followed by drinking water for 7 days. Kreyberg trichrom stain (acid mucopolysaccharides are stained blue).

mucosa (Figure 7). In some slides islands of squamous epithelium are found surrounded by colonic mucosa proximally and distally, but in most cases with deeper sections there appeared a continuity of squamous epithelium distally, suggesting an irregular shape of a squamous cell regenerate. Focally sometimes there is a moderate epithelial regeneratory atypia simulating dysplasia (Figure 5(b)). Most frequently it is found at the edge of chronic erosions.

We observed reepithelisation of distal part of colon as early as day 5 of DSS treatment in C57BL/6JOlaHsd but not in BALB/cAnNHsd mice. According to our experience reepithelisation of distal colon with squamous epithelium is frequent observation in C57BL/6JOlaHsd mice 1-4 weeks after DSS removal. The distance of reepithelisation with squamous epithelium that we measured under microscope ranged from $0.5-6.5 \mathrm{~mm}$ of colon length.

Histological changes seen in mouse DSS-induced colitis are the features of IBD in man, some of them of ulcerative colitis (regular rectal localization) and some of Crohn's disease (transmural inflammation with disseminated lymphoid follicles, focal lesions) [24, 25].

Besides all in Figure 1, mentioned factors that affect features of DSS-induced colitis preparation of tissues for histological examination may also be one of the reasons for discrepancy among studies. According to our experience as well as recommendation of other investigators [15] longitudinal sections as well as at least few sections of the same slide at intermediate distance of not less than $0.1 \mathrm{~mm}$ may better reflect the actual damage of DSS colitis than cross sections because of the patchy nature of DSS-induced lesions. In addition, the choice of staining method may also affect histological observations. For instance, cryptitis, crypt abscesses as well as squamous reepithelisation are easier to diagnose in sections stained with Kreyberg-Jareg method than hematoxylin-eosin method.

\section{The Role of Intestinal Flora in the Pathogenesis of DSS-Induced Colitis}

Intestinal microflora and their products have been implicated in the pathogenesis of human IBD [2, 26-28] and in several animal models [29]. The importance of the intestinal flora is directly supported by studies of some murine models where colitis is not observed when they are maintained in a gnotobiotic state but rapidly emerges 
TABLE 1: Susceptibility to DSS-induced colitis among inbred strains (adapted from [15]).

\begin{tabular}{lcccc}
\hline & Cecum & Proximal colon & Middle colon & Distal colon \\
\hline DBA/2J & BC & - & A & A \\
NON/LtJ & AB & - & A & A \\
NON.H2g7 & AB & - & AB & AB \\
$129 /$ SvPas & A & A & AB & B \\
NOD-scid & D & A & B & BC \\
C57BL/6J & BC & A & B & C \\
C3H/HeJ & D & - & AB & BC \\
NOD/LtJ & CD & A & & C \\
C3H/HeJBir & D & &
\end{tabular}

Strains that do not share the same letter in a column have significat differences in histological score for particular part of the colon after DSS administration. Letter A denotes the lowest histological score, while D denotes the highest histological score observed among the strains. — denotes no changes found in the colon (normal mucosa).

when they are reconstituted with bacteria that are considered normal constituents of luminal flora (explained in detail by Nell et al. [29]). It has been demonstrated that intestinal flora is implicated in the pathogenesis of DSS colitis in mice as well. First who suggested contribution of colonic bacteria or their products in the development of colitis in this model were Okayasu et al. [13]. They observed increased numbers of Enterobacteriaceae, Bacteroidaceae, and Clostridium spp. in the colons of mice affected by DSS colitis [13]. Another suggestion in this direction was given by Hans et al. [30], who reported that treatment with antibiotics reduced infiltration of granulocytes in the mucosa and improved histological signs of DSS colitis in acute phase [30]. The role of commensal bacteria and innate immunity in the development of intestinal inflammation has been further demonstrated by Hudcovic et al. [31]. When DSS-treated immunocompetent $\mathrm{BALB} / \mathrm{c}$ and immunodeficient SCID mice (lacking $\mathrm{T}$ and B lymphocytes) were maintained under conventional conditions, both strains developed substantial changes in the colon mucosa. BALB/c mice showed complete loss of the surface epithelium and severe infiltration of inflammatory cells. To evaluate susceptibility to DSS colitis in gnotobiotic conditions $\mathrm{BALB} / \mathrm{c}$ and SCID mice were transferred into isolators for germ-free rearing by special gnotobiological techniques. Interestingly, BALB/c and SCID mice reared in germ-free conditions (lacking any intestinal microflora) developed only minor signs of mucosal inflammation after DSS treatment [31]. This finding indicates that the presence of microflora facilitates the inflammation in DSS-induced colitis. Similar findings were observed by Kitajima et al. [32]. They used IQI/Jic mice maintained in germ-free conditions and their littermates that were conventionalized with feces obtained from SPF BALB/c mice three weeks before DSS administration. Histopathological findings revealed that IQI/Jic mice under germ-free conditions had no lesions indicative of colitis in the large intestine 3 days after 5\% DSS treatment, while IQI/Jic mice in conventional conditions developed focal erosions in the large bowel, mostly in the cecum and proximal colon. Interestingly, when both groups of mice were treated with $1 \%$ DSS for 14 days, mice under germ-free conditions developed slight inflammatory cell infiltration and edema in the lamina propria of the cecum and proximal colon and sever ulcerations, hemorrhages with frequent thrombi, and slight inflammatory cell infiltration in the distal colon. In the large bowel of IQI/Jic mice in conventional conditions only focal lesions of slight inflammatory cells infiltration and edema in mucosa along the whole large bowel were observed [32]. These findings demonstrate firstly that mucosal destruction caused by DSS occurs without the involvement of intestinal microflora and secondly that intestinal microflora may play an important modifying role in the susceptibility and responsiveness to DSS-induced damage of epithelial cells. The role of intestinal microflora in DSS-induced colitis is further investigated in mice deficient for different toll-like receptors (TLR), which function as sensors of microbial infection and are critical for the initiation of inflammatory and immune defence responses [33].

\section{The Role of Genetic Factors in the Pathogenesis of DSS-Induced Colitis}

Similar to IBD in humans [3], genetic factors play important role in DSS-induced colitis. Differences in susceptibility and responsiveness to DSS-induced colitis among inbred strains and substrains of mice have been identified. A quantitative histological analysis of DSS-induced colitis in nine mouse strains using a standardized protocol (3.5\% DSS of $36-45 \mathrm{kDa}$ molecular weight for 5 days) demonstrated major differences in DSS responsiveness among strains [15]. $\mathrm{C} 3 \mathrm{H} / \mathrm{HeJ}, \mathrm{NOD} / \mathrm{Ltj}$, and NOD-scid inbred strains are very susceptible to DSS-induced lesions, which develop in severe form mostly in the cecum. 129/SvPas and DBA/2J inbred mice are less susceptible to DSS-induced lesions and show various degrees of susceptibility to DSS, depending upon anatomical site as schematically demonstrated in the Table 1. Interestingly, severity of DSS-induced lesions in most inbred strains increased from proximal to the distal colon. A greater susceptibility to DSS-induced colonic but not cecal lesions was observed in male mice [15].

Stevceva et al. [35] demonstrated that $\mathrm{C} 3 \mathrm{H}$ mice are more susceptible to DSS colitis than $\mathrm{CBA} / \mathrm{H}$ and $\mathrm{BALB} / \mathrm{c}$. $\mathrm{C} 3 \mathrm{H}$ mice developed severe colitis with severe inflammatory 
TABLE 2: Differentially expressed genes in acute phase of DSS colitis that had been previously associated with human IBD [34].

\begin{tabular}{|c|c|c|c|c|c|}
\hline Gene & Name & Expression & Gene & Name & Expression \\
\hline Cytokine & & & \multicolumn{3}{|c|}{ Genes involved in tissue remodeling } \\
\hline$I L-6$ & Interleukine-6 & $\uparrow 2.6$ & $M m p 3$ & Stromelysin 1 & $\uparrow 22.5$ \\
\hline$I L-16$ & Interleukine-16 & $\downarrow 2.7$ & Mmp14 & Membrane type $1 \mathrm{MMP}$ & $\uparrow 2.1$ \\
\hline$I L-22$ & Interleukine-22 & $\uparrow 2.4$ & Timp1 & Tissue inhibitor of metalloproteinase 1 & $\uparrow 3.6$ \\
\hline \multicolumn{3}{|l|}{ Chemokine } & \multicolumn{3}{|c|}{ Regenerating islet-derived genes } \\
\hline CCL2 & JE (human:MCP-1) & $\uparrow 1.8$ & $\operatorname{Reg} 3 \gamma$ & Regenerating islet-derived $3 \gamma$ & $\uparrow 14.0$ \\
\hline CCL3 & MIP- $1 \alpha$ & $\uparrow 3.3$ & Pap & Pancreatitis-associated protein & $\uparrow 79.1$ \\
\hline CCL11 & Eotaxin & $\uparrow 3.3$ & S-100a9 & S-100 calcium-binding protein A9 (calgranulin B) & $\uparrow 14.0$ \\
\hline CXCL1 & $\mathrm{KC}(\mathrm{hu}: \mathrm{GRO} \alpha)$ & $\uparrow 2.9$ & \multicolumn{3}{|c|}{ Prostaglandin metabolism } \\
\hline CXCL5 & LIX (hu: ENA-78) & $\uparrow 6.6$ & Ptgs 2 & Prostaglandin-endoperoxidase synthase 2 (COX-2) & $\uparrow 4.1$ \\
\hline
\end{tabular}

Colitis was induced in $8 \mathrm{wk}$ female BALB/c mice that received 3\% DSS for 7 days and were sacrificed on day 7 . $\uparrow$ : significantly increased expression by denoted factor, $\downarrow$ : significantly decreased expression by denoted factor.

response predominantly involving ascending (proximal) colon and cecum, while $\mathrm{CBA} / \mathrm{H}$ and $\mathrm{BALB} / \mathrm{c}$ mice developed severe colitis mostly in distal colon. BALB/c mice, which are frequently used strain in DSS-colitis, are also less susceptible to DSS as IQI/Jic [32] or C57BL/6 [22]. The differences in the susceptibility to DSS-induced lesions were either due to genetic differences in the ability of the mucosa to withstand inflammatory damage, differences in the ability to limit the inflammatory response, or both. Melgar et al. [22] demonstrated differences in the progression of DSS colitis between two commonly used strains. After DSS withdrawal (one cycle), BALB/c mice recovered of DSS colitis, while in C57BL/6 mice colitis progressed into chronic phase [22]. The genetic factors contributing to DSS susceptibility in mice are unknown. Interestingly, some strains of mice are able to limit and eliminate DSS-induced inflammatory response in colon, while inflammatory process in C57BL/6 mice can not be repared but progresses into chronic form of colitis [22]. This indicates that genetic factors are importantly involved into regulations of inflammatory response, which is of great interest for further research.

\section{Pathogenesis of DSS-Induced Colitis}

It is widely accepted that DSS is toxic to colonic epithelial cells and causes defects in the epithelial barrier integrity, whereby increasing the colonic mucosal permeability to allow permeation of large molecules such as DSS. The mechanism of how DSS passes through the mucosal epithelial cells (transcellularly or paracellularly mediated via tight junctions) remains uncertain. First changes related to DSS were observed after 1 day of DSS treatment. These changes were loss of one of the components of tight junction complex $[36,37$ zonula occludens-1 (ZO-1) [38] and significantly increased expression of proinflammatory cytokines (TNF- $\alpha$, IL- $1 \beta$, IFN- $\gamma$, IL-10, and IL-12) in the colon [39]. By day 3 of DSS treatment significant increase in permeability to Evan's blue was observed [38]. At this time first histological changes in the colonic mucosa in the form of basal crypts loss and increased inflammatory cells infiltration can be seen. In acute phase of DSS colitis the impairment of epithelial barrier function is associated with loss and redistribution of the tight junction proteins such as occludin, ZO-1 [38], claudin- $1,-3,-4$, and -5 and an increased epithelial apoptotic ratio [40]. Altered expression of tight junction proteins and increased epithelial apoptosis were reported also in human IBD. It was proposed that imbalance between apoptosis and proliferation causes relevant leaks in the epithelial barrier. This is supported by the finding that both increased apoptosis and decreased proliferation of the epithelium take place in the acute phase of DSS colitis [41]. The single layered intestinal epithelium is a physical and immunological barrier that prevents direct contact of the intestinal mucosa with the luminal microbiota.

As evidenced by the amelioration of inflammation in germ-free animals and in mice treated with antibiotics $[27,30,31]$, DSS-induced breakdown of mucosal epithelial barrier function allows the entry of luminal antigens and microorganisms into the mucosa resulting in overwhelming inflammatory response.

Microarray analysis of the gene expression revealed that 173 genes were differentially and significantly expressed in the colon of DSS-treated mice by a factor of two or more when compared to control mice. Fifteen were previously associated with IBD in humans (shown in Table 2) [34]. Intestinal $\mathrm{Na}^{+}$-related transporters/channels and their regulatory proteins (NHE1,3, $\beta$-ENaC, and NHERF1,2) have been found to be downregulated in mouse colon in acute phase of DSS colitis and in mucosal biopsies from IBD patients (UC or CD) in active phase of disease [44].

7.1. Inflammatory Response and Mediators Involved in the Pathogenesis of DSS Colitis. Numerous inflammatory mediators have been implicated in the pathogenesis of human IBD. These include cytokines, eicosanoids, reactive oxygen species, nitric oxide, and complement system activation products [45-48]. Similarly, DSS-induced colitis is associated with the upregulation of different cytokines, chemokines, nitric oxide $[49,50]$, and inducible nitric oxide synthase (iNOS) [51]. Changes in production of inflammatory mediators in DSS-treated mice were investigated during different phases of colitis, in the serum and/or colon and by 
TABLE 3: Profile of inflammatory mediators in different phases of DSS-induced colitis in mice.

\begin{tabular}{|c|c|c|c|c|c|}
\hline Tissue/method & Analytes measured & acute DSS colitis & chronic DSS colitis & Mouse strain & ref. \\
\hline \multicolumn{6}{|c|}{7 days of DSS treatment } \\
\hline \multirow[t]{2}{*}{ Colon/RT PCR } & $\begin{array}{l}\text { IL-1, IL-4, IL-10, } \\
\text { IL-12, IFN } \gamma, \text { TNF } \alpha\end{array}$ & $\begin{array}{l}\uparrow \text { IL-1, IL-10, IL-12, } \\
\quad \uparrow \text { IFN- } \gamma, \text { TNF } \alpha\end{array}$ & - & $\mathrm{BALB} / \mathrm{c}$ & {$[42]$} \\
\hline & & 5 days of DSS treatment & $\begin{array}{c}5 \text { days of DSS followed by } \\
28 \text { days of water }\end{array}$ & & \\
\hline \multirow[t]{3}{*}{$\begin{array}{l}\text { Colon/ELISA, } \\
\text { MSI }\end{array}$} & $\begin{array}{l}\text { IL-1 } \alpha, \text { IL- } 1 \beta, \text { IL-12 } \\
\text { p40, IL-12 p70, IL-17, }\end{array}$ & $\begin{array}{c}\uparrow \mathrm{IL}-1 \alpha, \mathrm{IL}-1 \beta, \mathrm{IL}-12 \mathrm{p} 40 \\
\uparrow \mathrm{IL}-12 \mathrm{p} 70, \mathrm{IL}-17, \mathrm{IL}-6, \\
\uparrow \mathrm{G}-\mathrm{CSF}\end{array}$ & $\begin{array}{c}\uparrow \mathrm{IL}-1 \alpha, \mathrm{IL}-1 \beta, \mathrm{IL}-12 \mathrm{p} 40, \\
\uparrow \mathrm{IL}-12 \mathrm{p} 70, \mathrm{IL}-17, \mathrm{IL}-6, \\
\uparrow \mathrm{G}-\mathrm{CSF}\end{array}$ & C57BL/6J & {$[22]$} \\
\hline & IL-6, G-CSF, IL-18 & $\begin{array}{c}\uparrow \text { IL-1 } \alpha, \text { IL-1 } \beta, \text { IL-6, } \\
\uparrow \text { IL-18, G-CSF } \\
\end{array}$ & $\uparrow \mathrm{IL}-12 \mathrm{p} 40$ & $\mathrm{BALB} / \mathrm{c}$ & {$[22]$} \\
\hline & & 5 days of DSS treatment & $\begin{array}{c}5 \text { days of DSS followed by } 7 \\
\text { days of water }\end{array}$ & & \\
\hline \multirow[t]{2}{*}{ Colon/RT PCR } & $\begin{array}{l}\text { TNF- } \alpha \text {, IL-1 } \beta \text {, IL- } 6 \text {, } \\
\text { IL-10, IL-12, IFN- } \gamma \text {, } \\
\text { KC, MIP-2 }\end{array}$ & $\begin{array}{c}\uparrow \text { TNF- } \alpha, \text { IL- } 1 \beta, \text { IL-6, } \\
\uparrow \text { IL-10, IL-12, IFN- } \gamma, \\
\uparrow \text { KC, MIP-2 }\end{array}$ & $\begin{array}{c}\uparrow \text { TNF- } \alpha, \text { IL- } 1 \beta, \text { IL-6, } \\
\text { IL-10, } \\
\uparrow \text { IL-12, IFN- } \gamma, \text { KC, MIP-2 }\end{array}$ & $\mathrm{C} 57 \mathrm{BL} / 6 \mathrm{~J}$ & [39] \\
\hline & & 7 days of DSS treatment & $\begin{array}{c}4 \text { cycles of } 7 \text { days of DSS } \\
\text { followed by } 10 \text { days of water }\end{array}$ & & \\
\hline Serum/MSI & $\begin{array}{l}\text { IL-1 } \beta, \text { IL-2, IL-4, } \\
\text { IL-5, IL-6, IL-10, } \\
\text { IL-12, IL-17, IFN- } \gamma \text {, } \\
\text { TNF- } \alpha, \text { GM-CSF, } \\
\text { IP-10, KC, MCP-1, } \\
\text { MIG, MIP- } 1 \alpha\end{array}$ & $\uparrow$ IL-6, IL-17, TNF- $\alpha$, KC & $\uparrow$ IL-6, IFN- $\gamma$, IL-4, IL-10 & & [43] \\
\hline Colon/Western & $\begin{array}{l}\text { IL-6, IL-12, IL-23, } \\
\text { IL-17, IFN- } \gamma\end{array}$ & $\uparrow$ IL-6, IFN- $\gamma$, IL-17 & $\uparrow \mathrm{IL}-6$ & C57BL/6J & {$[43]$} \\
\hline
\end{tabular}

different methods (shown in Table 3). Increased expression of different inflammatory mediators (TNF- $\alpha$, IL- $1 \beta$, IFN- $\gamma$, IL-10, and IL-12) was observed as early as the first day of DSS treatment [39]. The production of these inflammatory mediators increased progressively during DSS treatment. Different profile of inflammatory mediators in acute and chronic phase of DSS colitis was demonstrated. Acute inflammation in DSS colitis converts to a predominant Th2mediated inflammatory response in the chronic state (lower levels of TNF- $\alpha$, IL-17, and KC and elevated levels of IL6 , IFN- $\gamma$, and IL-4, IL-10) [43]. Progressive upregulation in the transcripts for Th1 cytokines (IL-12, IFN- $\gamma$, IL-1, and TNF- $\alpha$ ) was observed with increasing dosage of DSS [42]. Different cytokine profile in chronic phase of DSS colitis was found between BALB/c and C57BL/6J mice, which reflected the severity of inflammation or infiltration of inflammatory cells in the colon found histologically [22].

These inflammatory mediators not only play a role in the pathogenesis of DSS-induced colitis but are important as intervention targets against colitis as excellently described by Kawada et al. [52]. Cytokine profile in DSS colitis correlates with clinical and histological parameters as well as barrier properties. Different expression depending on strain and phase of colitis provides this model as a useful tool to dissect the role of these cytokines in the induction of inflammation and recovery from it.

Recently comprehensive study of mucosal and systemic immune responses in $\mathrm{C} 57 \mathrm{BL} / 6 \mathrm{OlaH}$ sd mice exposed to $3 \%$
DSS for 6 days has been performed using immunofluorescent staining and flow cytometry analyses. It has been shown that adaptive immune responses in this mouse strain are induced during both acute and chronic phase of colitis in all organs tested, that are, colon, spleen, and mesenteric lymph nodes as early as day 1 of DSS treatment until the end (i.e., day 25) [23]. Interplay of neutrophils, dendritic cells, macrophages, and $\mathrm{T}$ and $\mathrm{B}$ cells among spleen, mesenteric lymph nodes, and colon in DSS-treated C57BL/6OlaHsd mice in temporal fashion is schematically represented in Figure 8.

\section{Geneticaly Modified Mice and DSS Treatment}

DSS-induced colitis is nowadays frequently used in genetically engineered mice (GEM), to study basic immunologic mechanisms of IBD and to elucidate the role of particular deleted $\left(^{-/-}\right)$or inserted $(\mathrm{Tg})$ gene in the pathogenesis of the colitis.

Toll-like receptors (TLR) are critical receptors and signal transducers for structurally conserved pathogenassociated molecular patterns of bacterial cell components (such as lipopolysaccharide) that provoke innate immune responses by stimulating macrophages/dendritic cells to produce proinflammatory cytokines. It has been shown that mice deficient for different TLR (TLR2, TLR4) or other molecules, which are implicated in signaling via TLR such as myeloid differential protein (MyD88), are very susceptible 
TABLE 4: Genetically engineered mouse models in the pathogenesis of DSS colitis.

\begin{tabular}{|c|c|c|c|c|c|c|c|c|}
\hline GEM model & Background (breeder) & Age gender $N$ & MS & MW of DSS & DSS treatment & End & $\mathrm{S}$ & Ref \\
\hline \multicolumn{9}{|l|}{ TLR2 ${ }^{-/-}$} \\
\hline \multicolumn{9}{|l|}{$\mathrm{TLR}^{-/-}$} \\
\hline \multirow[t]{2}{*}{ TLR $2 / 4^{-/-}$} & C57BL/10ScSn & $N=10-12$ & $\mathrm{nr}$ & $40 \mathrm{kDa}$ & $3.5 \%$ for 7 days & Day 8 & $\uparrow$ & {$[53]$} \\
\hline & & $5-8$ wks & & & & & & \\
\hline TLR4 $4^{-/-}$ & $\mathrm{C} 57 \mathrm{BL} / 6 \mathrm{~J}$ & Male, female & & & $2.5 \%$ for 5 days & Day 5 & & \\
\hline MyD88 $8^{-/-}$ & (Jax) & $N=5-6$ & $\mathrm{nr}$ & $36-50 \mathrm{kDa}$ & $2.5 \%$ for $5 / 7$ days & Day $12 / 14$ & $\uparrow$ & {$[54]$} \\
\hline \multicolumn{9}{|l|}{ TLR2 $2^{-/-}$} \\
\hline $\mathrm{TLR}^{-/-}$ & $\mathrm{F} 2$ & & & & & & & \\
\hline \multirow[t]{3}{*}{${\mathrm{MyD} 88^{-/-}}^{-}$} & $129 / \mathrm{SvJ} \times \mathrm{C} 57 \mathrm{BL} / 6$ & & SPF & $40 \mathrm{kDa}$ & $2 \%$ for 7 days & Day 0-28 & $\uparrow$ & {$[33]$} \\
\hline & & $8 \mathrm{wks}$ & & & & & & \\
\hline & & Male & & & $1.2 \%$ for 8 days & & & \\
\hline \multirow[t]{3}{*}{${\mathrm{MyD} 88^{-/-}}^{-}$} & $\mathrm{nr}$ & $N=10$ & SPF & $50 \mathrm{kDa}$ & $2.5 \%$ for 8 days & Day 8 & $\uparrow$ & {$[55]$} \\
\hline & & $10 \mathrm{wks}$ & & & & & & \\
\hline & $\mathrm{C} 57 \mathrm{BL} / 6$ & Male & & & & & & {$[56,57]$} \\
\hline \multirow[t]{2}{*}{ IL- $18^{\mathrm{Tg}}$} & (nr) & $N=20$ & SPF & $50 \mathrm{kDa}$ & $2 \%$ for 8 days & Day 12 & $\uparrow$ & \\
\hline & $\begin{array}{l}\text { C57BL/6 } \\
\text { (Taconic) }\end{array}$ & $\begin{array}{l}7-9 \text { wks } \\
N=11\end{array}$ & $\mathrm{nr}$ & $36-50 \mathrm{kDa}$ & $\begin{array}{c}3 \text { cycles of } \\
2 \% \text { for } 5 \text { days }+ \\
5 \text { days of water }\end{array}$ & $\begin{array}{c}\text { Day } 5 \\
\text { Day } 25 \\
\end{array}$ & $\downarrow$ & {$[58]$} \\
\hline IL- $15^{-/-}$ & $\mathrm{C} 57 \mathrm{BL} / 6 \mathrm{~J}$ & Male, female & & & & & & \\
\hline \multirow[t]{3}{*}{ TNF- $\alpha^{-/-}$} & (Shimizu, Japan) & $N=15$ & $\mathrm{nr}$ & $8 \mathrm{kDa}$ & $4.5 \%$ for 7 days & Day 7 & $\uparrow$ & {$[51]$} \\
\hline & & $8-10$ wks & & & & & & \\
\hline & & Male & & & & & & \\
\hline \multirow[t]{2}{*}{$\mathrm{MRP}^{-/-}$} & FVB & $N=8$ & SC & $40 \mathrm{kDa}$ & $3 \%$ for 7 days & Day 7 & $\uparrow$ & {$[59]$} \\
\hline & $\mathrm{C} 57 \mathrm{BL} / 6$ & $8-9$ wks & & & & Day 4,7 & & \\
\hline \multirow[t]{3}{*}{$\operatorname{Mtgr}^{-/-}$} & (nr) & Male, female & $\mathrm{nr}$ & $40-50 \mathrm{kDa}$ & $3 \%$ for 4 days & Wk 6, 10 & $\uparrow$ & {$[60]$} \\
\hline & & $7-8$ wks & & & & & & \\
\hline & $\mathrm{C} 57 \mathrm{BL} / 6$ & Male, female & & & $3 \%$ for 5 days & & & \\
\hline \multirow[t]{3}{*}{ SOCS $-1^{+/-}$} & $(\mathrm{nr})$ & $N=14$ & SPF & $36-50 \mathrm{kDa}$ & ( $4 \%$ for 7 days) & Day 14 & $\uparrow$ & {$[61]$} \\
\hline & & & & & 5 cycles of & & & \\
\hline & $\mathrm{C} 57 \mathrm{BL} / 6 \mathrm{~J}$ & $8-12$ wk & & & $2 \%$ for 7 days + & & & \\
\hline \multirow[t]{3}{*}{ IRF- $1^{-/-}$} & $(\mathrm{Jax})$ & $N=15$ & $\mathrm{nr}$ & $40 \mathrm{kDa}$ & 7 days of water & Wk 10 & $\uparrow$ & {$[62]$} \\
\hline & & $8-10 \mathrm{wk}$ & & & & & & \\
\hline & & Female & & & & & & \\
\hline \multirow[t]{2}{*}{$\operatorname{PPAR} \gamma^{\Delta \mathrm{IEpC}}$} & $\mathrm{nr}$ & $N=20$ & $\mathrm{nr}$ & $35-40 \mathrm{kDa}$ & $2.5 \%$ for 7 days & Day 7 & $\uparrow$ & {$[63]$} \\
\hline & C57BL/6J & & & & & & & \\
\hline \multirow[t]{2}{*}{$\operatorname{PPAR} \gamma^{\Delta \mathrm{CD} 4+}$} & $(\mathrm{nr})$ & $N=34$ & $\mathrm{nr}$ & $36-44 \mathrm{kDa}$ & $2.5 \%$ for 7 days & Day $0,2,7$ & $\uparrow$ & {$[64]$} \\
\hline & $\mathrm{C} 57 \mathrm{BL} / 6$ & & & & & & & \\
\hline $\mathrm{TPH}^{-/-}$ & (Taconic) & $N=10$ & $\mathrm{nr}$ & $40 \mathrm{kDa}$ & $5 \%$ for 5 days & Day 5 & $\downarrow$ & {$[65]$} \\
\hline $\mathrm{Bk} 2 \mathrm{R}^{-/-}$ & $\mathrm{C} 57 \mathrm{BL} / 6$ & $8-12 \mathrm{wk}$ & & & & & ns & \\
\hline \multirow[t]{2}{*}{$\mathrm{C} 3^{-1-}$} & (Jax) & $N=8$ & $\mathrm{nr}$ & $36-40 \mathrm{kDa}$ & $3 \%$ for 10 days & Day 10 & $\downarrow$ & {$[45]$} \\
\hline & $\mathrm{C} 57 \mathrm{BL} / 6$ & Male, female & & & & & & \\
\hline $\mathrm{iNOS}^{-/-}$ & (Jax) & $N=5$ & $\mathrm{nr}$ & $40 \mathrm{kDa}$ & $2.5 \%$ for 9 days & Day 3,9 & $\downarrow$ & {$[49,50]$} \\
\hline $\mathrm{eNOS}^{-/-}$ & & & & & & & $\downarrow$ & \\
\hline $\mathrm{nNOS}^{-/-}$ & $129 / \mathrm{Sv} \times \mathrm{C} 57 \mathrm{BL} / 6$ & Male, female & & & & & $\uparrow$ & \\
\hline e/nNOS ${ }^{-/-}$ & (Jax) & $N=5$ & $\mathrm{nr}$ & $40 \mathrm{kDa}$ & $2.5 \%$ for 9 days & Day 3,9 & ns & {$[49]$} \\
\hline
\end{tabular}


TABle 4: Continued.

\begin{tabular}{|c|c|c|c|c|c|c|c|c|}
\hline GEM model & Background (breeder) & Age gender $N$ & MS & MW of DSS & DSS treatment & End & $\mathrm{S}$ & Ref \\
\hline & & $5-10$ wks & & & & & & \\
\hline & C57BL/6 & Female & & & & & & \\
\hline \multirow[t]{3}{*}{$\mathrm{APN}^{-/-}$} & $(\mathrm{nr})$ & $N=5-7$ & $\mathrm{nr}$ & $40 \mathrm{kDa}$ & $2 \%$ for 5 days & Day 5,10 & $\downarrow$ & [66] \\
\hline & & $8-10$ wks & & & & & & \\
\hline & C57BL/6J & Male & & & & & & \\
\hline $\mathrm{APN}^{-/-}$ & (Clea Japan) & $N=11$ & SPF & $36-50 \mathrm{kDa}$ & $0.5 \%$ for 15 days & Day 15 & $\uparrow$ & [67] \\
\hline $\mathrm{Vhl}^{\Delta \mathrm{F} / \mathrm{F}}$ & & & & & & Day 5 & $\uparrow$ & \\
\hline Hif- $1 \alpha^{\Delta \mathrm{F} / \mathrm{F}}$ & & $6-8 \mathrm{wk}$ & & & $2.5 \%$ or $5 \%$ for & 1 year & ns & \\
\hline $\operatorname{Arnt}^{\Delta \mathrm{F} / \mathrm{F}}$ & $\mathrm{nr}$ & $\mathrm{nr}$ & $\mathrm{nr}$ & $35-40 \mathrm{kDa}$ & 5 days & & ns & [68] \\
\hline
\end{tabular}

GEM: genetically engineered mice, $N$ : number of mice pre group, MS: microbiological state, MW: molecular weight, S: susceptibility to DSS in comparison to wild-type mice (mice of the same strain without deletion), $\downarrow$ : significantly lower, SFP: specific pathogen-free conditions, SC: standard conditions, ns: nonsignificant, nr: not reported, $\uparrow$ : significantly higher, wk: week, TLR: toll-like receptor, MyD88: myeloid differential protein, IL: interleukine, MRP: multi drug resistant protein, Mtgr: myeloid translocation gene related-1, SOCS: suppressor of cytokine signaling, IRF: Interferon regulatory factor, PPAR: peroxisome proliferator-activated receptor, TPH: tryptophan hydroxylase, Bk2R: bradykinin type 2 receptor, C3: complement, APN: adiponectine, Vhl: von Hippel-Lindau tumor suppressor protein, Hif: hypoxia-inducible factor, Arnt: aryl hydrocarbon nuclear translocator.

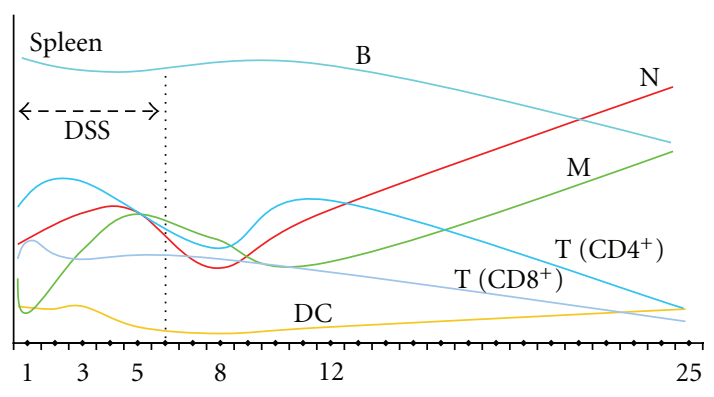

(a)

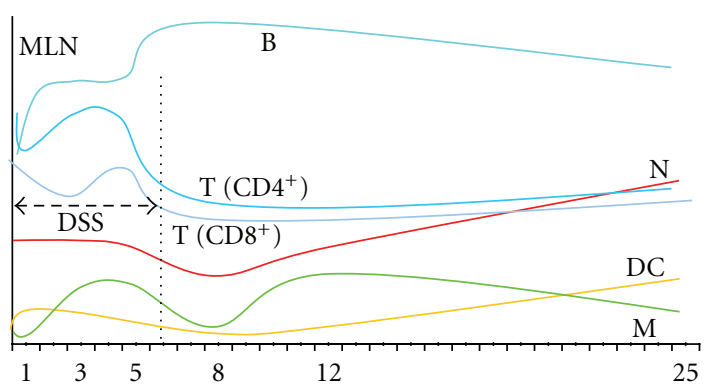

(b)

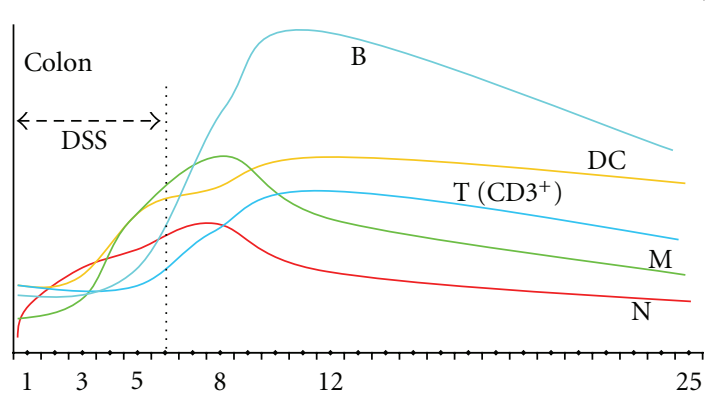

(c)

FIgURE 8: Schematic representation of mucosal (colon) and systemic (spleen, MLN) immune responses in C57BL/6OlaHsd mice exposed to $3 \%$ DSS for 6 days followed by water for 19 days. Measurements were made on day $0,1,3,5,8,12$, and 25 as denoted by numbers. Schematic representation is based on results obtained by Hall et al. [23]. MLN: mesenteric lymph nodes, N: neutrophils, M: macrophages, DC: dendritic cells, T: T cells, B: B cells.

to DSS colitis, indicating important protective role of these molecules in colitis $[33,53-55]$. Overproduction of IL18 or deletion of TNF- $\alpha$ has been shown to exacerbate DSS colitis $[51,56]$. On the other hand mice deficient for IL-15 showed reduced susceptibility to DSS colitis [58]. Mice deficit for IL-12 developed mild DSS colitis, while mice deficit for IL-18 developed severe colitis associated with high lethality [69]. Deletion of suppressor of cytokine signaling-1 (SOCS-1), which is a negative feedback molecule for cytokine signaling, increased susceptibility to DSS colitis, suggesting that SOCS-1 plays preventive role in the development of DSS-induced colitis in mice by inhibiting IFN- $\gamma /$ STAT1 signaling [61]. Interferon regulatory factor-1 (IRF-1) is a transcription factor stimulated by IFN- $\gamma$ and TNF- $\alpha$ that binds to the promoter region of inflammationrelated genes, such as IFN- $\alpha$, IFN- $\beta$, and iNOS. It is expressed in lymphocytes, monocytes, and a wide variety of other cell types, including enterocytes. Mice lacking IRF-1 transcription factor developed significantly increased DSSinduced colonic dysplasia [62]. Tryptophan hydroxylase1 (TPH1) catalyzes the rate-limiting step in the synthesis of 5-hydroxytryptamine (5-HT) from tryptophan. It is an 
important enteric mucosal signaling molecule influencing gut physiology (motor and secretory function) following inflammation and is considered important in maintaining intestinal homeostasis. However, mice lacking TPH1 had significantly reduced susceptibility to DSS colitis [65].

Taken together, GEM treated with DSS are valuable model to test different molecules, which are involved in the mediation of inflammation such as cytokines (IL-12, IL15 , IL-18, TNF- $\alpha$ ), nitric oxides (iNOS, eNOS, and nNOS), complement system activation products or other molecules involved in signaling of inflammation (SOCS-1, IRF-1), to further identify bacterial factors involved in maintaining intestinal homeostasis (TLR, MyD88), to investigate the role of particular factor when totally deleted or deleted only in particular types of cells such as intestinal, (PPAR $\gamma^{\triangle \mathrm{IEpC}}$; $\mathrm{Vhl}^{\Delta \mathrm{F} / \mathrm{F}} ;$ Hif- $1 \alpha^{\Delta \mathrm{F} / \mathrm{F}} ;$ Arnt $^{\Delta \mathrm{F} / \mathrm{F}}$ ) or CD4+ T cells (PPAR $\gamma^{\Delta \mathrm{CD} 4+}$ ) and to test therapeutic interventions based upon inhibition of particular gene expression strategies (TPH1, APN, and MRP1). In the Table 4 susceptibility to DSS-induced colitis in mice deficient for a particular gene is shown. Mouse background, gender, microbiological state, molecular weight of DSS, and DSS treatment, factors that importantly affect DSS colitis and need to be taken into account in designing investigation or evaluating results, are also stated.

\section{Conclusion}

DSS-induced model is simple to induce and not expensive, which makes it one of the most commonly used model of IBD to study various aspects of IBD such as pathogenesis, genetic predisposition to IBD, immune mechanisms, and role of microflora in the pathogenesis of IBD as well as bowel malignancy secondary to IBD. As demonstrated above, various factors may affect susceptibility to DSS and modify results. Representative examples of how important can be all mentioned details are studies where two groups of researchers investigated the role of adiponectine in DSS colitis. Both groups used in their studies the same mice model (mice with APN deletion) exposed to DSS treatment. They observed quite opposite results $[66,67]$. It is thus advisable to state and describe all details and conditions that may affect the DSS susceptibility.

\section{Acknowledgment}

This work was in part supported by ARRS (Slovenian Research Agency, Program P3-0054).

\section{References}

[1] R. B. Sartor and M. Muehlbauer, "Microbial host interactions in IBD: implications for pathogenesis and therapy," Current Gastroenterology Reports, vol. 9, no. 6, pp. 497-507, 2007.

[2] R. B. Sartor, "Microbial influences in inflammatory bowel diseases," Gastroenterology, vol. 134, no. 2, pp. 577-594, 2008.

[3] R. J. Xavier and D. K. Podolsky, "Unravelling the pathogenesis of inflammatory bowel disease," Nature, vol. 448, no. 7152, pp. 427-434, 2007.
[4] C. S. Gismera and B. S. Aladren, "Inflammatory bowel diseases: a disease (s) of modern times? Is incidence still increasing?" World Journal of Gastroenterology, vol. 14, no. 36, pp. 5491-5498, 2008.

[5] L. J. Zhu, X. Yang, and X. Q. Yu, "Anti-TNF-alpha therapies in systemic lupus erythematosus," Journal of Biomedicine and Biotechnology, vol. 2010, Article ID 465898, 8 pages, 2010.

[6] M. Neurath, I. Fuss, and W. Strober, "TNBS-colitis," International Reviews of Immunology, vol. 19, no. 1, pp. 51-62, 2000.

[7] S. Wirtz and M. F. Neurath, "Mouse models of inflammatory bowel disease," Advanced Drug Delivery Reviews, vol. 59, no. 11, pp. 1073-1083, 2007.

[8] S. Wirtz, C. Neufert, B. Weigmann, and M. F. Neurath, "Chemically induced mouse models of intestinal inflammation,” Nature Protocols, vol. 2, no. 3, pp. 541-546, 2007.

[9] R. M. De, E. Massi, M. L. Poeta et al., "The AOM/DSS murine model for the study of colon carcinogenesis: from pathways to diagnosis and therapy studies," Journal of Carcinogenesis, vol. 10, article 9, 2011.

[10] M. Kanneganti, M. Mino-Kenudson, and E. Mizoguchi, "Animal models of colitis-associated carcinogenesis," Journal of Biomedicine and Biotechnology, vol. 2011, Article ID 342637 , 23 pages, 2011.

[11] S. Melgar, L. Karlsson, E. Rehnstrom et al., "Validation of murine dextran sulfate sodium-induced colitis using four therapeutic agents for human inflammatory bowel disease," International Immunopharmacology, vol. 8, no. 6, pp. 836-844, 2008.

[12] T. Ohkusa, "Production of experimental ulcerative colitis in hamsters by dextran sulfate sodium and changes in intestinal microflora," Nihon Shokakibyo Gakkai Zasshi, vol. 82, no. 5, pp. 1327-1336, 1985.

[13] I. Okayasu, S. Hatakeyama, M. Yamada, T. Ohkusa, Y. Inagaki, and R. Nakaya, "A novel method in the induction of reliable experimental acute and chronic ulcerative colitis in mice," Gastroenterology, vol. 98, no. 3, pp. 694-702, 1990.

[14] S. Melgar, K. Engstrom, A. Jagervall, and V. Martinez, "Psychological stress reactivates dextran sulfate sodium-induced chronic colitis in mice," Stress, vol. 11, no. 5, pp. 348-362, 2008.

[15] M. Mahler, I. J. Bristol, E. H. Leiter et al., "Differential susceptibility of inbred mouse strains to dextran sulfate sodium-induced colitis," American Journal of Physiology, vol. 274, no. 3, part 1, pp. G544-G551, 1998.

[16] T. Vowinkel, T. J. Kalogeris, M. Mori, C. F. Krieglstein, and D. N. Granger, "Impact of dextran sulfate sodium load on the severity of inflammation in experimental colitis," Digestive Diseases and Sciences, vol. 49, no. 4, pp. 556-564, 2004.

[17] S. Kitajima, S. Takuma, and M. Morimoto, "Histological analysis of murine colitis induced by dextran sulfate sodium of different molecular weights," Experimental Animals, vol. 49, no. 1, pp. 9-15, 2000.

[18] I. Hirono, K. Kuhara, T. Yamaji, S. Hosaka, and L. Golberg, "Carcinogenicity of dextran sulfate sodium in relation to its molecular weight," Cancer Letters, vol. 18, no. 1, pp. 29-34, 1983.

[19] S. Kitajima, S. Takuma, and M. Morimoto, "Tissue distribution of dextran sulfate sodium (DSS) in the acute phase of murine DSS-induced colitis," Journal of Veterinary Medical Science, vol. 61, no. 1, pp. 67-70, 1999.

[20] H. S. Cooper, S. N. Murthy, R. S. Shah, and D. J. Sedergran, "Clinicopathologic study of dextran sulfate sodium experimental murine colitis," Laboratory Investigation, vol. 69, no. 2, pp. 238-249, 1993. 
[21] S. Kitajima, M. Morimoto, and E. Sagara, "A model for dextran sodium sulfate (DSS)-induced mouse colitis: bacterial degradation of DSS does not occur after incubation with mouse cecal contents," Experimental Animals, vol. 51, no. 2, pp. 203-206, 2002.

[22] S. Melgar, A. Karlsson, and E. Michaelsson, "Acute colitis induced by dextran sulfate sodium progresses to chronicity in $\mathrm{C} 57 \mathrm{BL} / 6$ but not in $\mathrm{BALB} / \mathrm{c}$ mice: correlation between symptoms and inflammation," American Journal of Physiology, vol. 288, no. 6, pp. G1328-G1338, 2005.

[23] L. J. Hall, E. Faivre, A. Quinlan, F. Shanahan, K. Nally, and S. Melgar, "Induction and activation of adaptive immune populations during acute and chronic phases of a murine model of experimental colitis," Digestive Diseases and Sciences, vol. 56, no. 1, pp. 79-89, 2011.

[24] I. Talbot, A. Price, and M. Salto-Tellez, Biopsy Pathology in Colorectal Disease, Hadder Arnol, 2nd edition, 2007.

[25] C. M. Fenoglio-Preiser, A. W. Noffsinger, G. N. Stemmermann, P. E. Lantz, and P. G. Isaacson, Gastrointestinal Pathology, LWW, 3rd edition, 2008.

[26] H. Tlaskalova-Hogenova, R. Stepankova, T. Hudcovic et al., "Commensal bacteria (normal microflora), mucosal immunity and chronic inflammatory and autoimmune diseases," Immunology Letters, vol. 93, no. 2-3, pp. 97-108, 2004.

[27] H. Tlaskalova-Hogenova, L. Tuckova, R. Stepankova et al., "Involvement of innate immunity in the development of inflammatory and autoimmune diseases," Annals of the New York Academy of Sciences, vol. 1051, pp. 787-798, 2005.

[28] S. Prakash, C. Tomaro-Duchesneau, S. Saha, and A. Cantor, "The gut microbiota and human health with an emphasis on the use of microencapsulated bacterial cells," Journal of Biomedicine and Biotechnology, vol. 2011, Article ID 981214, 12 pages, 2011.

[29] S. Nell, S. Suerbaum, and C. Josenhans, "The impact of the microbiota on the pathogenesis of IBD: lessons from mouse infection models," Nature Reviews Microbiology, vol. 8, no. 8, pp. 564-577, 2010.

[30] W. Hans, J. Scholmerich, V. Gross, and W. Falk, "The role of the resident intestinal flora in acute and chronic dextran sulfate sodium-induced colitis in mice," European Journal of Gastroenterology and Hepatology, vol. 12, no. 3, pp. 267-273, 2000.

[31] T. Hudcovic, R. Stepankova, J. Cebra, and H. TlaskalovaHogenova, "The role of microflora in the development of intestinal inflammation: acute and chronic colitis induced by dextran sulfate in germ-free and conventionally reared immunocompetent and immunodeficient mice," Folia Microbiologica, vol. 46, no. 6, pp. 565-572, 2001.

[32] S. Kitajima, M. Morimoto, E. Sagara, C. Shimizu, and Y. Ikeda, "Dextran sodium sulfate-induced colitis in germ-free IQI/Jic mice," Experimental Animals, vol. 50, no. 5, pp. 387-395, 2001.

[33] S. Rakoff-Nahoum, J. Paglino, F. Eslami-Varzaneh, S. Edberg, and R. Medzhitov, "Recognition of commensal microflora by toll-like receptors is required for intestinal homeostasis," Cell, vol. 118, no. 2, pp. 229-241, 2004.

[34] A. A. te Velde, F. de Kort, E. Sterrenburg et al., "Comparative analysis of colonic gene expression of three experimental colitis models mimicking inflammatory bowel disease," Inflammatory Bowel Diseases, vol. 13, no. 3, pp. 325-330, 2007.

[35] L. Stevceva, P. Pavli, G. Buffinton, A. Wozniak, and W. F. Doe, "Dextran sodium sulphate-induced colitis activity varies with mouse strain but develops in lipopolysaccharide-unresponsive mice," Journal of Gastroenterology and Hepatology, vol. 14, no. 1, pp. 54-60, 1999.
[36] N. Ichikawa-Tomikawa, K. Sugimoto, S. Satohisa, K. Nishiura, and H. Chiba, "Possible Involvement of tight junctions, extracellular matrix and nuclear receptors in epithelial differentiation," Journal of Biomedicine and Biotechnology, vol. 2011, Article ID 253048, 10 pages, 2011.

[37] P. Laprise, "Emerging role for epithelial polarity proteins of the crumbs family as potential tumor suppressors," Journal of Biomedicine and Biotechnology, vol. 2011, Article ID 868217, 9 pages, 2011.

[38] L. S. Poritz, K. I. Garver, C. Green, L. Fitzpatrick, F. Ruggiero, and W. A. Koltun, "Loss of the tight junction protein ZO-1 in dextran sulfate sodium induced colitis," Journal of Surgical Research, vol. 140, no. 1, pp. 12-19, 2007.

[39] Y. Yan, V. Kolachala, G. Dalmasso et al., "Temporal and spatial analysis of clinical and molecular parameters in dextran sodium sulfate induced colitis," PLoS One, vol. 4, no. 6, Article ID e6073, 2009.

[40] R. Mennigen, K. Nolte, E. Rijcken et al., "Probiotic mixture VSL\#3 protects the epithelial barrier by maintaining tight junction protein expression and preventing apoptosis in a murine model of colitis," American Journal of Physiology, vol. 296, no. 5, pp. G1140-G1149, 2009.

[41] Y. Araki, K. Mukaisyo, H. Sugihara, Y. Fujiyama, and T. Hattori, "Increased apoptosis and decreased proliferation of colonic epithelium in dextran sulfate sodium-induced colitis in mice," Oncology Reports, vol. 24, no. 4, pp. 869-874, 2010.

[42] B. Egger, M. Bajaj-Elliott, T. T. MacDonald, R. Inglin, V. E. Eysselein, and M. W. Büchler, "Characterisation of acute murine dextran sodium sulphate colitis: cytokine profile and dose dependency," Digestion, vol. 62, no. 4, pp. 240-248, 2000.

[43] P. Alex, N. C. Zachos, T. Nguyen et al., "Distinct cytokine patterns identified from multiplex profiles of murine DSS and TNBS-induced colitis," Inflammatory Bowel Diseases, vol. 15, no. 3, pp. 341-352, 2009.

[44] S. Sullivan, P. Alex, T. Dassopoulos et al., "Downregulation of sodium transporters and NHERF proteins in IBD patients and mouse colitis models: potential contributors to IBDassociated diarrhea," Inflammatory Bowel Diseases, vol. 15, no. 2, pp. 261-274, 2009.

[45] F. Lu, S. M. Fernandes, and A. E. Davis III, "The role of the complement and contact systems in the dextran sulfate sodium-induced colitis model: the effect of $\mathrm{Cl}$ inhibitor in inflammatory bowel disease," American Journal of Physiology, vol. 298, no. 6, pp. G878-G883, 2010.

[46] P. López, C. Gutiérrez, and A. Suárez, "IL-10 and TNFalpha genotypes in SLE," Journal of Biomedicine and Biotechnology, vol. 2010, Article ID 838390, 11 pages, 2010.

[47] B. Marshall and S. Swain, "Cytotoxic CD4 T cells in antiviral immunity," Journal of Biomedicine and Biotechnology, vol. 2011, Article ID 954602, 8 pages, 2011.

[48] P. K. Yadav, C. Chen, and Z. Liu, "Potential role of NK cells in the pathogenesis of inflammatory bowel disease," Journal of Biomedicine and Biotechnology, vol. 2011, Article ID 348530, 6 pages, 2011.

[49] P. L. Beck, R. Xavier, J. Wong et al., "Paradoxical roles of different nitric oxide synthase isoforms in colonic injury," American Journal of Physiology, vol. 286, no. 1, pp. G137G147, 2004.

[50] P. L. Beck, Y. Li, J. Wong et al., "Inducible nitric oxide synthase from bone marrow-derived cells plays a critical role in regulating colonic inflammation," Gastroenterology, vol. 132, no. 5, pp. 1778-1790, 2007.

[51] Y. Naito, T. Takagi, O. Handa et al., "Enhanced intestinal inflammation induced by dextran sulfate sodium in tumor 
necrosis factor-alpha deficient mice," Journal of Gastroenterology and Hepatology, vol. 18, no. 5, pp. 560-569, 2003.

[52] M. Kawada, A. Arihiro, and E. Mizoguchi, "Insights from advances in research of chemically induced experimental models of human inflammatory bowel disease," World Journal of Gastroenterology, vol. 13, no. 42, pp. 5581-5593, 2007.

[53] M. M. Heimesaat, A. Fischer, B. Siegmund et al., "Shift towards pro-inflammatory intestinal bacteria aggravates acute murine colitis via toll-like receptors 2 and 4," PLoS One, vol. 2, no. 7, article e662, 2007.

[54] M. Fukata, K. S. Michelsen, R. Eri et al., “Toll-like receptor4 is required for intestinal response to epithelial injury and limiting bacterial translocation in a murine model of acute colitis," American Journal of Physiology, vol. 288, no. 5, pp. G1055-G1065, 2005.

[55] A. Araki, T. Kanai, T. Ishikura et al., "MyD88-deficient mice develop severe intestinal inflammation in dextran sodium sulfate colitis," Journal of Gastroenterology, vol. 40, no. 1, pp. 16-23, 2005.

[56] T. Hoshino, Y. Kawase, M. Okamoto et al., "Cutting edge: IL18-transgenic mice: in vivo evidence of a broad role for IL-18 in modulating immune function," Journal of Immunology, vol. 166, no. 12, pp. 7014-7018, 2001.

[57] T. Ishikura, T. Kanai, K. Uraushihara et al., "Interleukin-18 overproduction exacerbates the development of colitis with markedly infiltrated macrophages in interleukin-18 transgenic mice," Journal of Gastroenterology and Hepatology, vol. 18, no. 8, pp. 960-969, 2003.

[58] K. Yoshihara, T. Yajima, C. Kubo, and Y. Yoshikai, "Role of interleukin 15 in colitis induced by dextran sulphate sodium in mice," Gut, vol. 55, no. 3, pp. 334-341, 2006.

[59] H. T. Ten, P. Drillenburg, J. Wijnholds, A. A. te Velde, and S. J. H. van Deventer, "Differential susceptibility of multidrug resistance protein-1 deficient mice to DSS and TNBS-induced colitis," Digestive Diseases and Sciences, vol. 47, no. 9, pp. 20562063, 2002.

[60] J. A. Martinez, C. S. Williams, J. M. Amann et al., "Deletion of mtgr 1 sensitizes the colonic epithelium to dextran sodium sulfate-induced colitis," Gastroenterology, vol. 131, no. 2, pp. 579-588, 2006.

[61] J. Horino, M. Fujimoto, F. Terabe et al., "Suppressor of cytokine signaling-1 ameliorates dextran sulfate sodiuminduced colitis in mice," International Immunology, vol. 20, no. 6, pp. 753-762, 2008.

[62] E. E. Mannick, R. L. Cote, J. R. Schurr et al., "Altered phenotype of dextran sulfate sodium colitis in interferon regulatory factor-1 knock-out mice," Journal of Gastroenterology and Hepatology, vol. 20, no. 3, pp. 371-380, 2005.

[63] M. Adachi, R. Kurotani, K. Morimura et al., "Peroxisome proliferator activated receptor $\gamma$ in colonic epithelial cells protects against experimental inflammatory bowel disease," Gut, vol. 55, no. 8, pp. 1104-1113, 2006.

[64] A. J. Guri, S. K. Mohapatra, W. T. Horne, R. Hontecillas, and J. Bassaganya-Riera, "The role of T cell PPAR gamma in mice with experimental inflammatory bowel disease," $B M C$ Gastroenterology, vol. 10, article 60, 2010.

[65] J. E. Ghia, N. Li, H. Wang et al., "Serotonin has a key role in pathogenesis of experimental colitis," Gastroenterology, vol. 137, no. 5, pp. 1649-1660, 2009.

[66] R. Fayad, M. Pini, J. A. Sennello et al., "Adiponectin deficiency protects mice from chemically induced colonic inflammation," Gastroenterology, vol. 132, no. 2, pp. 601-614, 2007.

[67] T. Nishihara, M. Matsuda, H. Araki et al., "Effect of adiponectin on murine colitis induced by dextran sulfate sodium," Gastroenterology, vol. 131, no. 3, pp. 853-861, 2006.

[68] Y. M. Shah, S. Ito, K. Morimura et al., "Hypoxia-inducible factor augments experimental colitis through an mif-dependent inflammatory signaling cascade," Gastroenterology, vol. 134, no. 7, pp. 2036-2048, 2008.

[69] H. Takagi, T. Kanai, A. Okazawa et al., "Contrasting action of IL-12 and IL-18 in the development of dextran sodium sulphate colitis in mice," Scandinavian Journal of Gastroenterology, vol. 38, no. 8, pp. 837-844, 2003. 


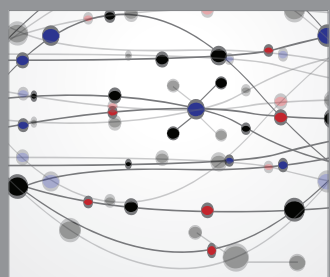

The Scientific World Journal
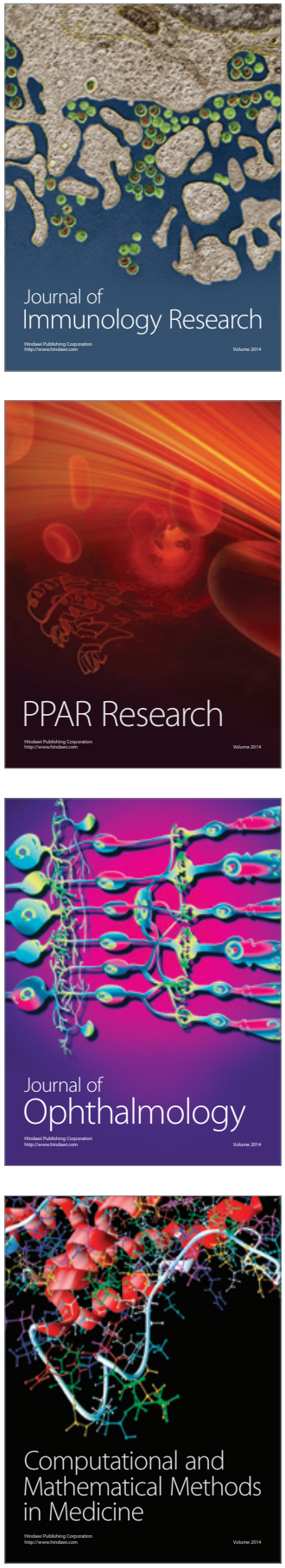

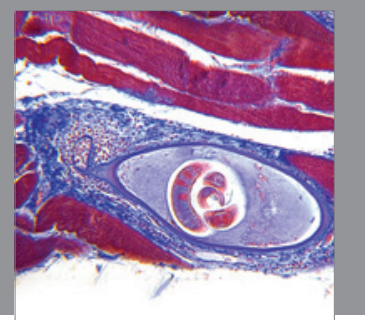

Gastroenterology

Research and Practice
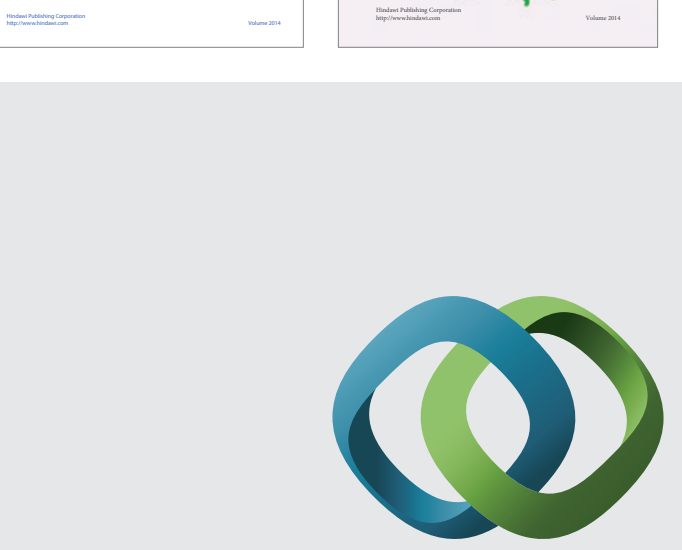

\section{Hindawi}

Submit your manuscripts at

http://www.hindawi.com
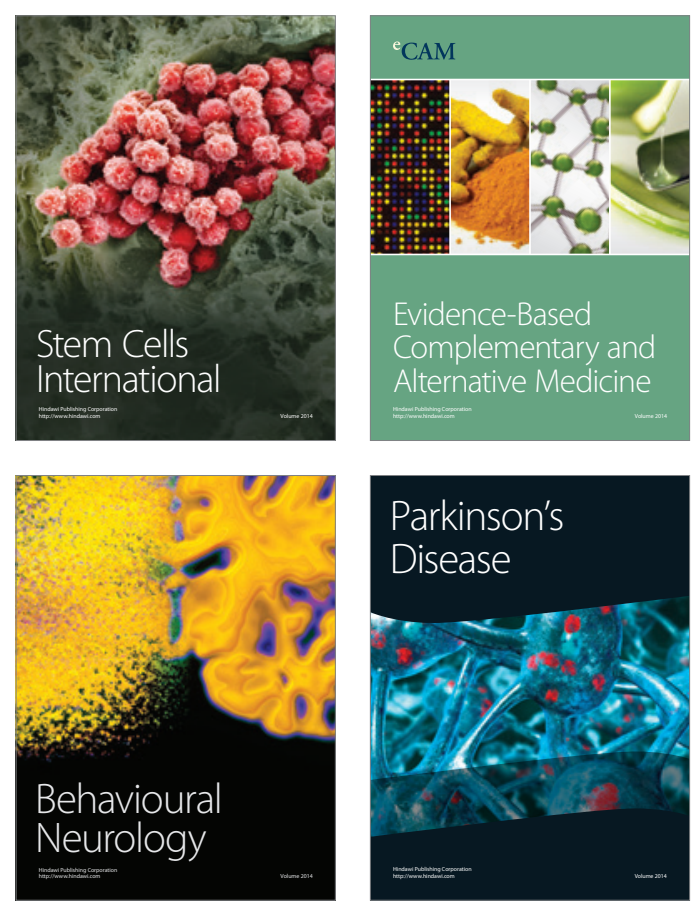

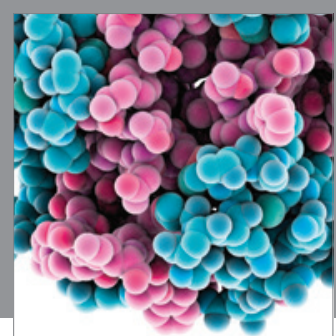

Journal of
Diabetes Research

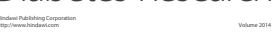

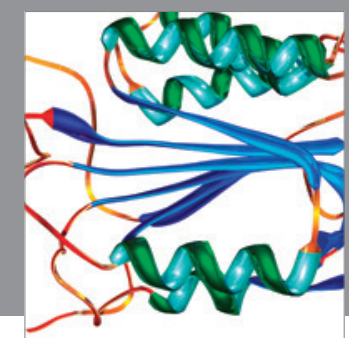

Disease Markers
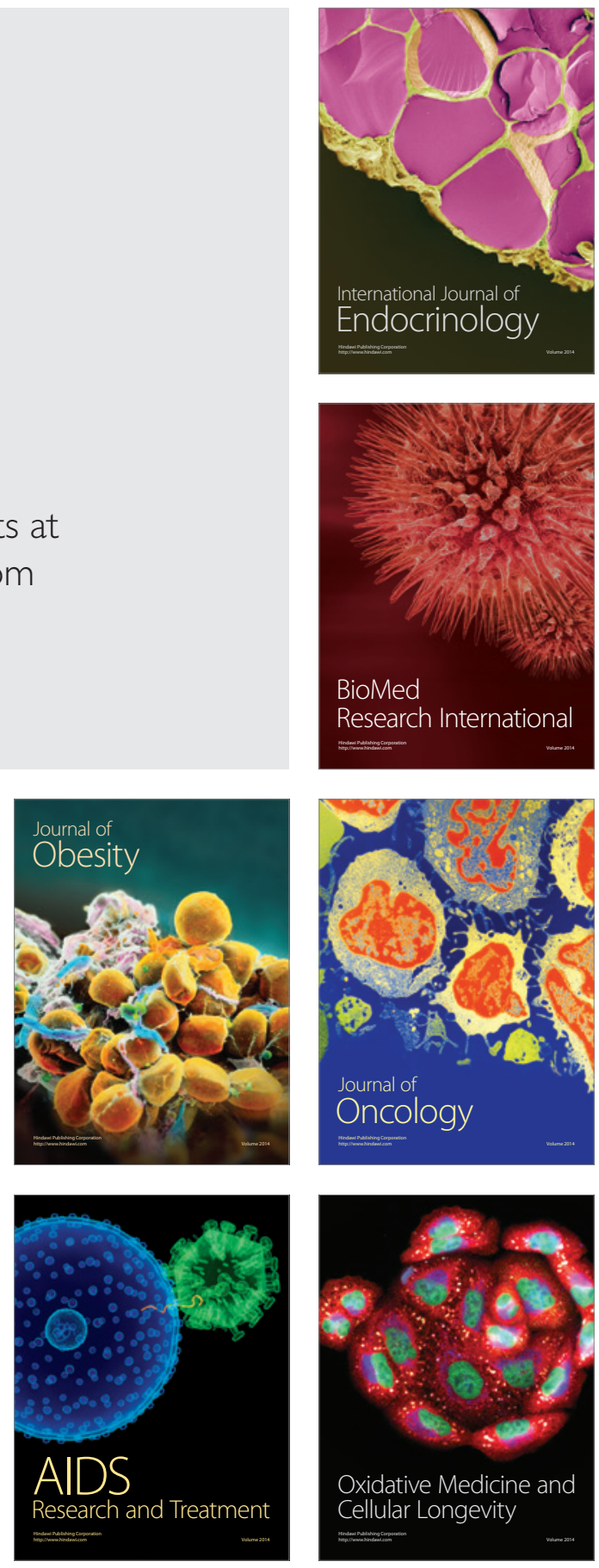